\title{
Synthesis, Characterization and Microwave Absorption of Carbon-coated Cu Nanocapsules
}

\author{
Yuping Sun ${ }^{a}$, Chao Feng ${ }^{b}$, Xianguo Liu ${ }^{b *}$, Siu Wing Or ${ }^{c}$, Chuangui Jin ${ }^{b}$ \\ ${ }^{a}$ Center for Engineering practice and Innovation Education, Anhui University of Technology, \\ Maanshan 243032, PR China \\ ${ }^{b}$ School of Materials Science and Engineering, Anhui University of technology, \\ Maanshan 243002, PR China \\ 'Department of Electrical Engineering, The Hong Kong Polytechnic University, \\ Hung Hom, Kowloon, Hong Kong
}

Received: June 7, 2013; Revised: November 11, 2013

\begin{abstract}
The microstructure and microwave absorption of carbon-coated $\mathrm{Cu}$ nanocapsules have been investigated. Carbon-coated $\mathrm{Cu}$ nanocapsules have been synthesized by an arc-discharge method. The paraffin- $\mathrm{Cu} / \mathrm{C}$ nanocapsules composite shows excellent electromagnetic (EM) absorption properties. An optimal reflection loss (RL) value of $-40.0 \mathrm{~dB}$ is reached at $10.52 \mathrm{GHz}$ for a layer $1.9 \mathrm{~mm}$ thickness. RL exceeding $-20 \mathrm{~dB}$ can be realized in any interval within the $1-18 \mathrm{GHz}$ range by choosing an appropriate thickness of the absorbent layer between 1.1 and $10.0 \mathrm{~mm}$. Theoretical simulation for the microwave absorption using the transmission line theory agrees reasonably well with the experimental results. The EM-wave absorption properties of nanocapsules materials are illustrated by means of an absorption-tube-map. The carbon-coated $\mathrm{Cu}$ nanocapsule is an attractive candidate for EM-wave absorption, which significantly enriches the family of EM-wave nanoabsorbents.
\end{abstract}

Keywords: nanocomposites, carbon, microwave absorbers

\section{Introduction}

Since the discovery of fullerenes, the carbon-fullerene family of materials have become a focus of much research and exhibited fundamental importance in the advancement of science and engineering ${ }^{1,2}$. In recent decades, much attention has been paid to carbon-coated metal nanoparticles, namely 'nanocapsules'. In recent years, with the development of local electronic devices, microwave communication, and the rising pollution of electromagnetic (EM) interference, materials with EM-wave absorption in a wide frequency range, with strong absorption, low density, and low cost are more and more desirable ${ }^{3}$. The EM-wave absorption properties of magnetic material-based nanocomposites and heterostructured nanocomposites have been intensely investigated, because of the synergetic effect between magnetic and dielectric losses ${ }^{4-7}$. Among the candidates for EM-wave absorbers, magnetic nanocapsules with carbon as shells have attracted intensive interest on account of the following facts: (1) the large saturation magnetization and high Snoek limit, (2) the suppression of the eddy current phenomenon, and (3) being composites with different kinds of EM-absorber materials ${ }^{8}$. However, the EM-wave absorption properties of non-magnetic nanocapsules with carbon as shells have been seldom reported. Carbon-coated $\mathrm{Cu}$ nanocapsules were prepared by an arc discharge method in a methane $\left(\mathrm{CH}_{4}\right)$ atmosphere, in which the special microstructures with graphite shells and $\mathrm{Cu}$ cores result in a high relative complex permittivity and dielectric loss, exhibiting promising application as a new type of EM

*e-mail: liuxianguohugh@gmail.com wave shield/absorbent ${ }^{2}$. On the other hand, the graphite shells are outstanding microwave absorption materials due to their dielectric properties, which play an important role in improving the disperse properties of nanocapsules ${ }^{9,10}$.

Actually, $\mathrm{Cu}$ nanoparticles possess many good properties such as electric, optical, thermal and lubricating, etc $^{11-15}$. A broad arena in engineering applications is also attributed to these particles and is attracting an increasing number of scientists.Carbon-coated $\mathrm{Cu}$ nanocapsules for sensor applications had been produced using a modified flame spray synthesis unit under highly reducing conditions ${ }^{13}$. Zhang et al. reported the synthesis of carboncoated $\mathrm{Cu}$ nanocapsules by means of an arc discharge method in $\mathrm{a} \mathrm{CH}_{4}$ atmosphere, which consists of carboncoated $\mathrm{Cu}$ nanocapsules and onion-like fullerenes ${ }^{2}$. Since then, significant progress has been made in the syntheses of carbon-coated $\mathrm{Cu}$ nanocapsules. As well known, the complex permeability, permittivity, the EM impedance match and the microstructure of the absorber determine the EM -absorption properties. Although carbon-coated $\mathrm{Cu}$ nanocapsules have been synthesized by various methods, the EM-absorption properties of carbon-coated $\mathrm{Cu}$ nanocapsules have been seldom studied. In this study, we have synthesized carbon-coated $\mathrm{Cu}$ nanocapsules by an arc discharge technique. The EM properties and microwave absorption properties of carbon-coated $\mathrm{Cu}$ nanocapsules have been deeply investigated. Furthermore, an absorptiontube-map has been presented for designing better absorbents with materials of $\mu_{r}=1$. In order to verify the theoretical 
calculation of microwave absorption using the transmission line theory from permittivity and permeability data, the experimental results of microwave absorption have been carried.

\section{Experimental}

Arc discharge is a powerful method for preparing nanoparticles and nanocapsules, which has been described previously elsewhere ${ }^{16-19}$. Briefly, the pure $\mathrm{Cu}$ ingot to be evaporated served as the anode on the water cooled cooper stage. The upper carbon needle served as the cathode. Ar (16 $000 \mathrm{~Pa}$ ) gas and $\mathrm{H}_{2}(4000 \mathrm{~Pa})$ and $40 \mathrm{~mL}$ liquid ethanol were introduced into the evacuated chamber $\left(1.0 \times 10^{-2} \mathrm{~Pa}\right)$ before a potential was applied between the cathode and the anode. The current was maintained at $100 \mathrm{~A}$ for $0.5 \mathrm{~h}$. When the arc time reached $0.5 \mathrm{~h}$, the pressure of the chamber can reach 1 atmospheric pressure because of the decomposition of ethanol and the expand of the gas with increasing the temperature. The electric arc can be controlled during operation through adjusting the distance between the two electrodes. After being passivated in air for $8 \mathrm{~h}$, the carbon-coated $\mathrm{Cu}$ nanocapsules were collected in the top of the chamber. In order to get the enough nanocapsules for the measurement of reflection loss, the above experiment is repeated several times under the same experiment conditions.

The composition and phase purity of the as-synthesized samples were analyzed by X-ray diffraction (XRD) at $40 \mathrm{kV}$ voltage and $50 \mathrm{~mA}$ current with $\mathrm{Cu} \mathrm{K} \alpha$ radiation $(\lambda=1.5418 \AA$ ). Transmission electron microscopy (TEM) and high-resolution TEM (HRTEM) images were obtained on a JEOL JEM-2010 transmission electron microscope at an acceleration voltage of $200 \mathrm{kV}$. The paraffin- $\mathrm{Cu}$ nanocapsules composite was prepared by uniformly mixing $\mathrm{Cu}$ nanocapsules with paraffin, as described in

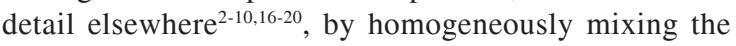
nanocapsule with paraffin and pressing them into cylindershaped compacts. Then the compact was cut into toroidal shape with $7.00 \mathrm{~mm}$ outer diameter and $3.04 \mathrm{~mm}$ inner diameter. The EM parameters are measured for paraffin$\mathrm{Cu}$ nanocapsules composite containing 40 wt. $\% \mathrm{Cu}$ nanocapsules, using an Agilent 8722ES network analyzer. The microwave-absorbing characteristics were evaluated by measuring the reflection loss using an HP8757E scalar quantity network analyzer in the $1-18 \mathrm{GHz}$ band range, and the sample sheets $(180 \mathrm{~mm} \times 180 \mathrm{~mm})$ were mounted onto an aluminum substrate. All the measurements were performed at room temperature. Coaxial method was used to determine the EM parameters of the toroidal samples in a frequency range of $1-18 \mathrm{GHz}$ with a transverse electromagnetic mode. The VNA was calibrated for the full two-port measurement of reflection and transmission at each port. The complex permittivity and complex permeability were calculated from S-parameters tested by the VNA, using the simulation program of Reflection/Transmission Nicolson-Ross model. Air line holder is VNA-8722ES and VNA- HP8757E accessory and Nicolson-Ross model is used on the $85071 \mathrm{E}$ Materials Measurement Software. Air coaxial line was used to determine the EM parameters of the toroidal samples in a frequency range of 1-18 GHz. The mismatches between the cable and sample holder can be eliminated by means of the change of electric delay method in the calibration accessories of network analyzer. The RL coefficient curves were calculated from the relative permeability and permittivity for a given frequency and absorber thickness, according to the following equations:

$$
\begin{aligned}
& Z_{\text {in }}=Z_{0}\left(\mu_{r} / \varepsilon_{r}\right)^{1 / 2} \tanh \left[j(2 \pi f d / c)\left(\mu_{r} \varepsilon_{r}\right)^{1 / 2}\right] \\
& R L=20 \lg \left|\left(Z_{\text {in }}-Z_{0}\right) /\left(Z_{\text {in }}+Z_{0}\right)\right|
\end{aligned}
$$

where $f$, is the frequency of the EM-wave, $d$, the thickness of the absorber, $c$, the velocity of light, $Z_{0}$, the impedance of free space and $Z_{i n}$, the input impedance of the absorber.

\section{Results and Discussion}

Figure 1a shows the XRD pattern of carbon-coated $\mathrm{Cu}$ nanocapsules. As shown in Figure 1a, the main peak located at $2 \theta=43.48^{\circ}, 50.44^{\circ}$ and $74.13^{\circ}$, respectively, corresponds to the (111), (200) and (220) planes of $\mathrm{Cu}$ with face centered cubic structure, and the lattice constant of the (111) planes is approximately $2.08 \AA$.It is then evident that the carbon atoms from the carbon needle hardly affect the lattice constant of $\mathrm{Cu}$ nanoparticles to form a $\mathrm{Cu}-\mathrm{C}$ solid solution. Figure $1 \mathrm{~b}$ and $\mathrm{c}$ show the TEM and HRTEM images of carbon-coated $\mathrm{Cu}$ nanocapsules. As can be seen, most of the $\mathrm{Cu}$ nanocapsules are spherical in shape, with the mean diameter in the range 10-30 nm. Moreover, from the HRTEM of Figure 1c, it is clearly noted that the whole surface of the nanoparticles is coated by a graphitic multi-layered carbon shell around 1-2 $\mathrm{nm}$ in thickness, which is thinner than that of carbon-coated $\mathrm{Fe}$, Ni or $\mathrm{Sn}$ nanocapsules ${ }^{3,10}$. The interplaner spacing of $0.34 \mathrm{~nm}$ in the coating is approximately close to that of the bulk graphite (002) plane, which is accordance with the previous results ${ }^{2,3,10}$. Moreover, it can be found that
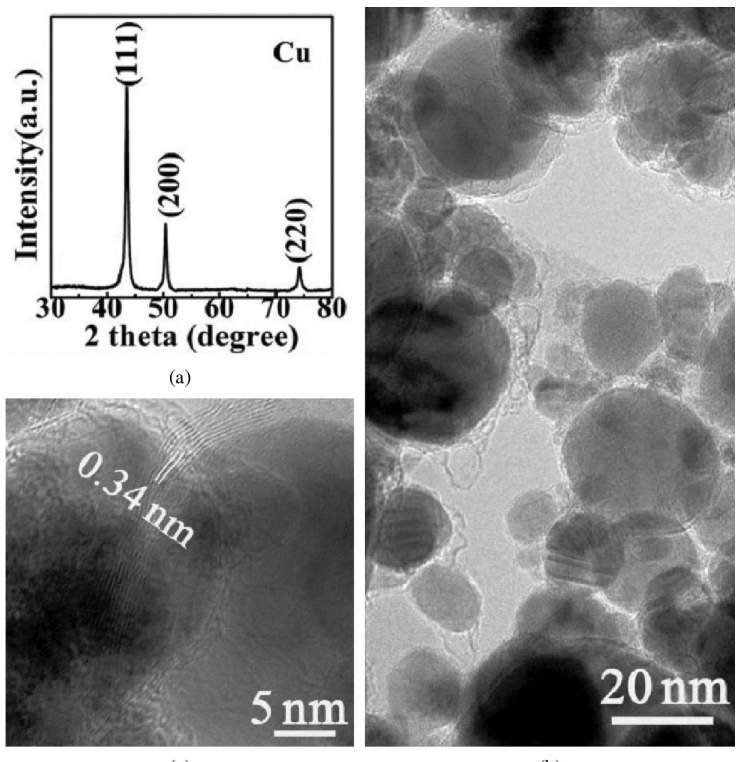

(c)

(b)

Figure 1. (a) XRD pattern, (b) TEM and (c) HRTEM images of carbon-coated $\mathrm{Cu}$ nanocapsules. 
many lattice defects occur in the carbon shell, including collapses, unevenness, dislocations, etc. The many lattice defects can lead to the high electrical resistivity, which is useful to significantly absorb the microwave energy ${ }^{21}$. In our experiments, during the thermal evaporation process, the $\mathrm{Cu}$ nanoparticles were formed at first and then covered by carbon. The formed carbon-coated $\mathrm{Cu}$ nanocapsules fall on the surface of the chamber.

To obtain the EM-absorption properties of carboncoated $\mathrm{Cu}$ nanocapsules, $\mathrm{RL}$ of the $\mathrm{Cu}$ nanocapsules was calculated using the relative complex permeability and permittivity at a given frequency and layer thickness according to the transmission-line theory ${ }^{3,22}$. Figure 2 represents the frequency dependence of the complex relative permittivity $\left(\varepsilon_{r}\right)$ and permeability $\left(\mu_{r}\right)$ of the paraffin- $\mathrm{Cu}$ nanocapsules composite. As shown in Figure 2a, maximum/ minimum values can be found below/above the resonant frequencies in the real part ( $\left.\varepsilon^{\prime}\right)$ curve. Accordingly, a peak is observed in the imaginary part ( $\varepsilon$ ") curve near the resonant frequencies. The resonant frequency of $\varepsilon_{r}$ in the current frequency range is $7.97 \mathrm{GHz}$, as shown in Figure 2a. Since 1990s, considerable attempts have been done to get an exact solution of the permittivity of heterogeneous mixtures ${ }^{23}$. Tinga et. $\mathrm{al}^{24}$ have studied multiphase inclusions in the form of confocal ellipsoidal shells dispersed in a host material, which is similar to the present case where carbon-coated $\mathrm{Cu}$ nanocapsules are dispersed in a paraffin matrix. Following the effective-medium theory of three-phase inclusions ${ }^{3,24}$, the permittivity of paraffin- $\mathrm{Cu}$ nanocapsules composite seems to originate from the special geometric structures of the $\mathrm{Cu}$ nanocapsules inclusions, the intrinsic permittivity of each component in the paraffin-nanocapsules composite $(\mathrm{Cu}, \mathrm{C}$ and paraffin), and the dispersion (volume fraction) of the nanocapsules ${ }^{3}$.

As shown in Figure $2 \mathrm{~b}$, the real part ( $\left.\mu^{\prime}\right)$ of $\mu_{r}$ and the imaginary part ( $\mu$ ") of $\mu_{r}$ are almost constant in the $1-18 \mathrm{GHz}$ with values of $1 \pm 0.03$ and $0 \pm 0.03$, respectively. This permeability is expected for a material that has no magnetic properties. The real part of the permeability tends to slightly decrease with increasing frequency. However, a slight decrease might be expected, in a conductive, non-magnetic material; on increasing frequency, eddy currents start shielding of the material, thus reducing its permeability to 0 (at infinite frequency), as if it were a perfect diamagnet (like a superconductor below its critical temperature) ${ }^{3}$. In any case, the permeability in Figure $2 b$ is that of a non-magnetic system, as expected. It is worthy noted that the negative $\mu$ " exists in our measured data, as shown in Figure $2 b$.

To further examine the microwave absorption abilities of the carbon-coated $\mathrm{Cu}$ nanocapsules, $\mathrm{RL}$ coefficient as a function of absorbing thickness $d$ and frequency $f$ were calculated, as shown in Figure 3a, according to Equation 1 and 2. The optimal RL or the dip in RL corresponds to the occurrence of the maximum absorption or the minimal reflection of the microwave power for the particular thickness. An optimal RL value of $-40.0 \mathrm{~dB}$, corresponding to $99.99 \%$ absorption, is observed at $10.52 \mathrm{GHz}$ for a layer $1.9 \mathrm{~mm}$ thickness. It is worth noting that the absorbent with a thickness of $1.1 \mathrm{~mm}$ has RL values exceeding $-20 \mathrm{~dB}$ at high frequencies in broad frequency ranges, which is thinner than the previous reported results ${ }^{3-5,8-10,16-20,25-27}$. As shown in Figure 3b, for all frequencies within the $1-18 \mathrm{GHz}$ range, $\mathrm{RL}$ values exceeding $-20 \mathrm{~dB}$ can be obtained by selecting an appropriate thickness of the absorbent layer between 1.1 and $10.0 \mathrm{~mm}$. Compared with other carboncoated nanoparticles or nanowires (e.g., $\mathrm{Sn} / \mathrm{C}^{[3]}, \mathrm{Ni} / \mathrm{C}^{[28]}$, $\mathrm{FeNi} / \mathrm{C}^{[10]}, \mathrm{FeCo} / \mathrm{C}^{[29]}$, and $\mathrm{FeCoNi} /$ carbon nanotubes ${ }^{[30]}$ ), the non-magnetic carbon-coated $\mathrm{Cu}$ nanocapsules present quite different and excellent EM-wave absorption properties, which may be due to the special microstructure of the $\mathrm{Cu}$ nanocapsules, the size of the $\mathrm{Cu}$ nanocapsules, and also the weight fraction of paraffin- $\mathrm{Cu}$ nanocapsules composite ${ }^{3}$. Generally, there are two mechanisms of energy attenuation in materials: magnetic loss and dielectric loss ${ }^{3}$. However, due to the non-magnetic nature, the present $\mathrm{Cu}$ nanocapsules absorb the EM-wave mainly by dielectric losses. And the loss phenomena associated with dielectric mixtures are due to the various polarizations caused by relative displacement of electrons and nuclei, dipolar orientations and interfacial (Maxwell-Wagner) effects at the boundaries between the

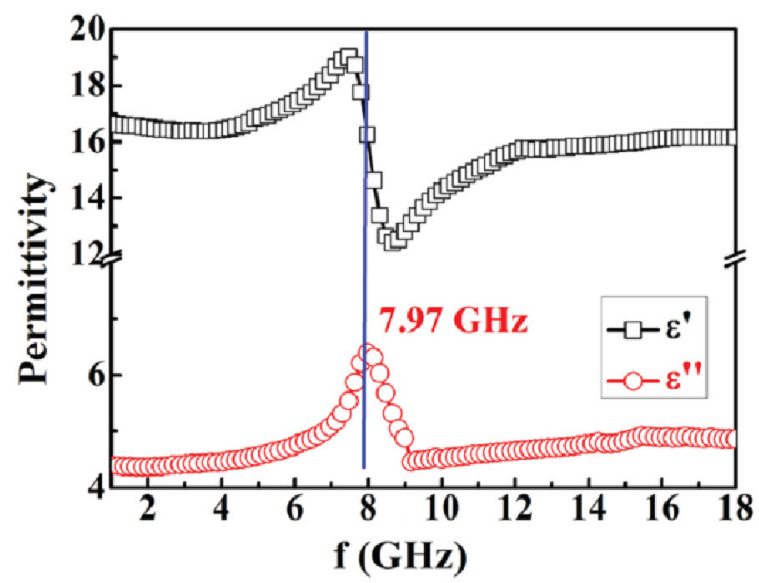

(a)

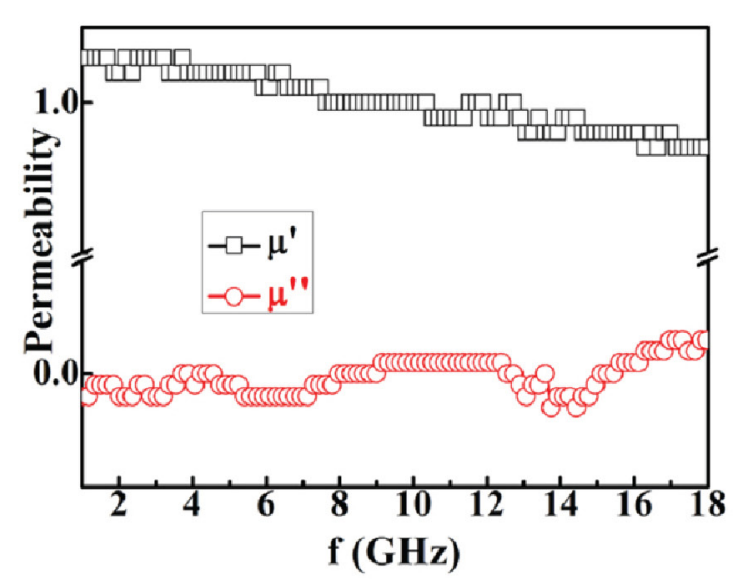

(b)

Figure 2. (a) Relative permittivity and (b) relative permeability of paraffin-Cu nanocapsules composite as a function of frequency. 


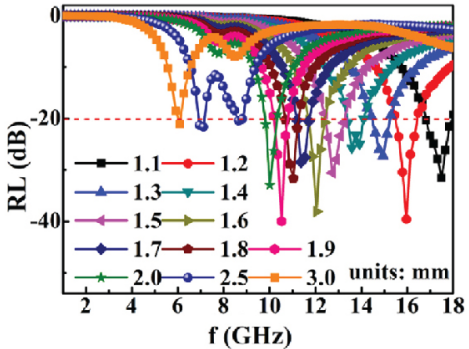

(a)

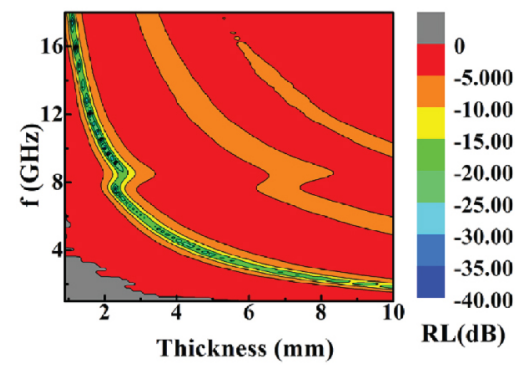

(b)

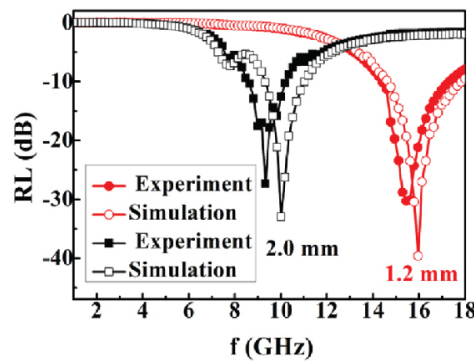

(c)

Figure 3. (a) Simulated RL coefficient curves of the paraffin-Cu nanocapsules composite as a function of frequency. (b) Two-dimensional representation of RL coefficient derived from the measured and of the paraffin-Cu nanocapsules composite. (c) RL coefficient curves of the composites with the different thickness as the function of frequency for simulation and experiment.

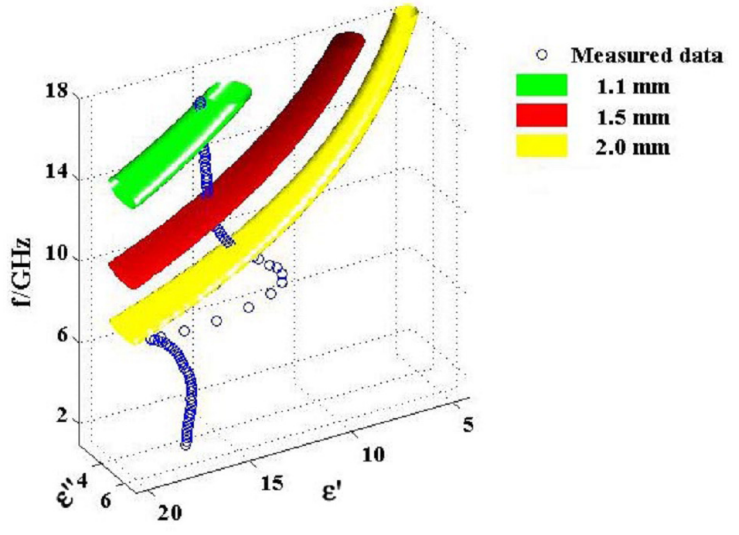

Figure 4. Absorption-tubes for materials with $\mu_{r}=1$. For illustrations, layers with the thickness of $1.1,2.0$ and $3.0 \mathrm{~mm}$ are given; open circles are the measured relative complex permittivity of the paraffin-Cu nanocapsules composite.

mixture components ${ }^{3}$. The lossy behavior becomes even more pronounced in the conducting $\mathrm{Cu}$ and dielectric carbon interfaces of the $\mathrm{Cu}$ nanocapsules ${ }^{3,31}$. In addition, the simulated results show that the RL peak frequency is closely related to the thickness and moves to the lower frequency with the increase of sample thickness, as shown in Figure 3a. It is worthy noted that there is a small peak at around $8 \mathrm{GHz}$ for the layer thickness below $2.0 \mathrm{~mm}$, which is explained by the resonant frequency of $\varepsilon_{r}$ at $7.97 \mathrm{GHz}$ in Figure 2a. However, there are two clear RL peaks for the sample with the thickness above $2.0 \mathrm{~mm}$, ascribed to the quarter-wavelength cancellation by thickness ${ }^{21}$. For the sample with the thickness above $2.0 \mathrm{~mm}$, the small peak at around $8 \mathrm{GHz}$ disappears, due to the broaden effect by the successive strong RL peaks.

Figure $3 \mathrm{c}$ shows the simulation and experimental results for paraffin-Cu nanocapsules composite with the thickness of $1.2 \mathrm{~mm}$ and $2.0 \mathrm{~mm}$, respectively. Both the experimental results show that the center frequencies were shifted a little from the theoretical predictions. In the view of the complexity of EM absorption, the theoretical results agree reasonably well with the experimental results in both the curve pattern and absolute values. The slight discrepancy between the simulated results and experimental ones can be caused by several factors, such as error in fabrication of specimens and measurement of permittivity and reflection $\operatorname{loss}^{32}$.

In order to study RL given by Equation 2, the relations between the variables of $\varepsilon_{r}, \mu_{r}, d$ and $f$ is of great interest to be investigated. Considerable attention has been paid to these kinds of heterogeneous systems, in which nanocapsules with magnetic core and dielectric shell are dispersed in dielectric matrixes (rubber, paraffin or epoxy resin) ${ }^{3}$. However, only a few approximations and numerical methods can be used to resolve Equation 2 to obtain the RL values, because it is too complicated to deal with the six variables in it $^{3}$. In the present study, the situation can be simplified as $\mu^{\prime}=1$ and $\mu "=0$, due to the non-magnetic nature of $\mathrm{Cu}$ nanocapsules. By simulating Equation 2 with $\mu_{r}=1$, effective absorption $(\mathrm{RL}<-20)$ 'tubes' for the layer thicknesses of $1.1 \mathrm{~mm}$, $1.5 \mathrm{~mm}$ and $2.0 \mathrm{~mm}$ were obtained, respectively. As shown in Figure 4, the areas where the measured permittivity of $\mathrm{Cu}$ nanocapsules goes through the tubes are effective absorption locations. This simulation agrees well with the results in Figure 4, as discussed before. Figure 4 reveals a great potential for non-magnetic materials in EM-wave absorption applications. The absorption tube-map also suggests a general route for finding better absorbents with materials of $\mu_{r}=1$. For composite with a certain layer thickness, one is only able to get RL values $<-20 \mathrm{~dB}$ in the whole $1-18 \mathrm{GHz}$ range when the measured permittivity spectra are all located within the tubes of the corresponding thickness ${ }^{3}$.

\section{Conclusions}

Carbon-coated $\mathrm{Cu}$ nanocapsules have been synthesized by a modified arc discharge method, in which $\mathrm{Cu}$ nanoparticles as cores and carbon as shells. Many lattice defects occur in the carbon shell, including collapses, unevenness, dislocations, etc, which can lead to the high electrical resistivity. By choosing an appropriate thickness of the absorbent layer between 1.1 and $10.0 \mathrm{~mm}$, RL values exceeding $-20 \mathrm{~dB}$ can be realized in any interval within the $1-18 \mathrm{GHz}$ range. There is a small peak at around $8 \mathrm{GHz}$ for the layer thickness below $2.0 \mathrm{~mm}$, which is explained by the resonant frequency of $\varepsilon_{r}$ at $7.97 \mathrm{GHz}$. However, there are two clear RL peaks for the sample with the thickness above 
$2.0 \mathrm{~mm}$, ascribed to the quarter-wavelength cancellation by thickness. For the sample with the thickness above $2.0 \mathrm{~mm}$, the small peak at around $8 \mathrm{GHz}$ disappears, due to the broaden effect by the successive strong RL peaks. Theoretical calculation of microwave absorption using the transmission line theory from permittivity and permeability data agrees reasonably well with the experimental results. An absorption-tube-map is presented for designing better absorbents with materials of $\mu_{r}=1$. As a result, the nonmagnetic carbon-coated $\mathrm{Cu}$ nanocapsules are attractive

\section{References}

1. Krätschmer W, Lamb LD, Fostiropoulos K and Huffman DR. $\mathrm{C}_{60}$ : a new form of carbon. Nature 1990; 347:354-358. http:// dx.doi.org/10.1038/347354a0

2. Zhang XF, Dong XL, Huang H, Wang DK, Lv B and Lei JP. High permittivity from defective carbon-coated $\mathrm{Cu}$ nanocapsules. Nanotechnology 2007; 18(27):275701. http:// dx.doi.org/10.1088/0957-4484/18/27/275701

3. Wang ZH, Han Z, Geng DY and Zhang ZD. Synthesis, characterization and microwave absorption of carbon-coated $\mathrm{Sn}$ nanorods. Chemical Physics Letters. 2010; 489(4-6):187-190. http://dx.doi.org/10.1016/j.cplett.2010.02.056

4. Chen YJ, Gao P, Zhu CL, Wang RX, Wang LJ, Cao MS et al. Synthesis, magnetic and electromagnetic wave absorption properties of porous $\mathrm{Fe}_{3} \mathrm{O}_{4} / \mathrm{Fe} / \mathrm{SiO}_{2}$ core/shell nanorods. Journal of Applied Physics. 2009; 106(5):054303. http://dx.doi. org/10.1063/1.3204958

5. Chen YJ, Gao P, Wang RX, Zhu CL, Wang LJ, Cao MS et al. Porous $\mathrm{Fe}_{3} \mathrm{O}_{4} / \mathrm{SnO}_{2}$ core/shell nanorods: synthesis and electromagnetic properties. Journal of Physics Chemistry C. 2009; 113(23):10061-10064. http://dx.doi.org/10.1021/ jp902296z

6. Zou GZ, Cao MS, Lin HB, Jin HB, Kang YQ and Chen YJ. Nickel layer deposition on $\mathrm{SiC}$ nanoparticles by simple electroless plating and its dielectric behaviors. Powder Technology. 2006; 168(2):84-88. http://dx.doi.org/10.1016/j. powtec.2006.07.002

7. Shi XL, Cao MS, Yuan J, Zhao QL, Kang YQ, Fang XY et al. Nonlinear resonant and high dielectric loss behavior of CdS $/ \alpha-$ $\mathrm{Fe}_{2} \mathrm{O}_{3}$ heterostructure nanocomposites. Applied Physics Letters. 2008; 93(18):183118. http://dx.doi.org/10.1063/1.3023074

8. Liu XG, Jiang JJ, Geng DY, Li BQ, Han Z and Zhang ZD. Dual nonlinear dielectric resonance and strong natural resonance in Ni/ZnO nanocapsules. Applied Physics Letters. 2009; 94(5):053119. http://dx.doi.org/10.1063/1.3079393

9. Liu JR, Itoh M, Horikawa T, Machida K, Sugimoto S and Maeda T. Gigahertz range electromagnetic wave absorbers made of amorphous-carbon-based magnetic nanocomposites. Journal of Applied Physics. 2005; 98(5):054305. http://dx.doi. org/10.1063/1.2009082

10. Liu XG, Li B, Geng DY, Cui WB, Yang F et al. (Fe, Ni)/C nanocapsules for electromagnetic-wave-absorber in the whole Ku-band. Carbon. 2009; 47(2):470-474. http://dx.doi. org/10.1016/j.carbon.2008.10.028

11. Xu BS, Guo JJ, Wang XM, Liu XG and Ichinose H. Synthesis of carbon nanocapsules containing $\mathrm{Fe}, \mathrm{Ni}$ or Co by arc discharge in aqueous solution. Carbon. 2006; 44(13):2631-2634. http:// dx.doi.org/10.1016/j.carbon.2006.04.024

12. Hayashi $\mathrm{T}$, Hirono $\mathrm{S}$, Tomita $\mathrm{M}$ and Umemura S. Magnetic thin films of cobalt nanocrystals encapsulated in graphitelike carbon. Nature. 1996; 381:772-774. http://dx.doi. org/10.1038/381772a0 candidates for EM-wave absorption, which significantly enriches the family of EM-wave absorbents.

\section{Acknowledgements}

This study has been supported partly by the National Natural Science Foundation of China (Grant Nos. 51201002 and 21071003), by the Research Grants Council of the HKSAR Government (PolyU 5236/12E), and The Hong Kong Polytechnic University (G-YK59 and 4-ZZ7L).

13. Athanassiou EK, Grass RN and Stark W. Large-scale production of carbon-coated copper nanoparticles for sensor applications. Nanotechnology. 2006; 17(6):1668-1673. http:// dx.doi.org/10.1088/0957-4484/17/6/022

14. Celep G, Cottancin E, Lermé J, Pellarin M, Arnaud L, Huntzinger JR et al. Optical properties of copper clusters embedded in alumina: An experimental and theoretical study of size dependence. Physical Review B. 2004; 70(16):165409. http://dx.doi.org/10.1103/PhysRevB.70.165409

15. Armelao L, Barreca D, Bottaro G, Gasparotto A, Gross S, Maragno $\mathrm{C}$ et al. Recent trends on nanocomposites based on $\mathrm{Cu}, \mathrm{Ag}$ and Au clusters: A closer look. Coordination Chemistry Reviews. 2006; 250(11-12):1294-1314. http://dx.doi. org/10.1016/j.ccr.2005.12.003

16. Liu XG, Or SW, Ho SL, Cheung CC, Leung CM, Han Z et al. Full X-Ku band microwave absorption by $\mathrm{Fe}(\mathrm{Mn}) / \mathrm{Mn}_{7} \mathrm{C}_{3} / \mathrm{C}$ core/shell/shell structured nanocapsules. Journal of Alloys and Compounds. 2011; 509(37):9071-9075. http://dx.doi. org/10.1016/j.jallcom.2011.06.031

17. Liu XG, Liu XH, Zhang Q and Zhang ZD. Exchange bias in $\mathrm{CrN} / \mathrm{Co}$ nanocomposites consisting of $\mathrm{CrN}$-coated $\mathrm{Co}$ nanocapsules and $\mathrm{CrN}$ nanoparticles. Journal of Alloys and Compounds. 2009; 486(1-2):14-17. http://dx.doi.org/10.1016/j. jallcom.2009.06.183

18. Liu XG, Or SW, Ho SL, Wang H and Zhang ZD. Electromagnetic wave absorption properties of mechanically mixed $\mathrm{Nd}_{2} \mathrm{Fe}_{14} \mathrm{~B} / \mathrm{C}$ microparticles. Journal of Alloys and Compounds. 2011; 509(6):2929-2932. http://dx.doi.org/10.1016/j. jallcom.2010.11.161

19. Liu XG, Geng DY, Jiang JJ, Du J, Yang F, Xie ZG et al. High dielectric loss in graphite-coated Ti nanocapsules. Journal of Nanoscience and Nanotechnology. 2010; 10(4):2366-2369. http://dx.doi.org/10.1166/jnn.2010.2159

20. Liu XG, Geng DY, Meng H, Shang PJ and Zhang ZD. Microwave-absorption properties of $\mathrm{ZnO}$-coated iron nanocapsules. Applied Physics Letters. 2008; 92(17):173117. http://dx.doi.org/10.1063/1.2919098

21. Wang T, Han R, Tan GG, Wei JJ, Qiao L and Li FS. Reflection loss mechanism of single layer absorber for flake-shaped carbonyl-iron particle composite. Journal of Applied Physics. 2012;112(10):104903. http://dx.doi.org/10.1063/1.4767365

22. Yusoff AN, Abdullah MH, Ahmad SH, Jusoh SF, Mansor AA and Hamid SAA. Electromagnetic and absorption properties of some microwave absorbers. Journal of Applied Physics. 2002; 92(2):876-881. http://dx.doi.org/10.1063/1.1489092

23. Sheen J, Hong ZW, Liu W, Mao WL and Chen CA. Study of dielectric constants of binary composites at microwave frequency by mixture laws derived from three basic particle shapes. European Polymer Journal. 2009; 45(4):1316-1321. http://dx.doi.org/10.1016/j.eurpolymj.2008.08.002 
24. Tinga WR, Voss WAG and Blossey DF. Generalized approach to multiphase dielectric mixture theory. Journal of Applied Physics. 1973; 44(9):3897-3903. http://dx.doi. org/10.1063/1.1662868

25. Deng LJ and Han MG. Microwave absorbing performances of multiwalled carbon nanotube composites with negative permeability. Appliled Physics Letters. 2007; 91(2):023119. http://dx.doi.org/10.1063/1.2755875

26. Liu XG, Feng C, Or SW, Sun YP, Jin CG, Li WH et al. Investigation on microwave absorption properties of $\mathrm{CuO}$ / $\mathrm{Cu}_{2} \mathrm{O}$-coated $\mathrm{Ni}$ nanocapsules as wide-band microwave absorbers. RSC Advances. 2013; 3(34):14590-14594. http:// dx.doi.org/10.1039/c3ra40937f

27. Liu XG, Or SW, Sun YP, Jin CG and Lv YH. Influence of a graphite shell on the thermal, magnetic and electromagnetic characteristics of Fe nanoparticles. Journal of Alloys and Compounds. 2013; 548:239-244. http://dx.doi.org/10.1016/j. jallcom.2012.09.006

28. Han Z, Li D, Wang H, Liu XG, Geng DY and Zhang ZD. Broadband electromagnetic-wave absorption by $\mathrm{FeCo} / \mathrm{C}$ nanocapsules. Applied Physics Letters. 2009; 95(2):023114. http://dx.doi.org/10.1063/1.3177067

29. Lv RT, Kang FY, Gu JL, Gui XC, Wei JQ, Wang KJ et al. Carbon nanotubes filled with ferromagnetic alloy nanowires: Lightweight and wide-band microwave absorber. Applied Physics Letters. 2008; 93(22):223105. http://dx.doi. org/10.1063/1.3042099

30. Perambur BV. Complex permittivity of a conductorloaded dielectric. Journal of Physics: Condensed Matter. 1990; 2(22):4935-4947. http://dx.doi.org/10.1088/0953$8984 / 2 / 22 / 014$

31. Park KY, Lee SE, Kim CG and Han JH. Fabrication and electromagnetic characteristics of electromagnetic wave absorbing sandwich structures. Composite Science and Technology. 2006; 66(3-4):576-584. http://dx.doi. org/10.1016/j.compscitech.2005.05.034

32. Liu XG, Feng C, Or SW, Jin CG, Xiao F, Xia AL et al. Synthesis and electromagnetic properties of Al/AlOx-coated Ni nanocapsules. Materials Research Bulletin. 2013; 48(10): 3887-3891. 